\title{
A possível atuação do Ecomuseu da Amazônia no desenvolvimento do turismo de base comunitária na llha de Cotijuba - PA
}

\author{
The possible action of the Amazonian ecomuseum in the \\ development of community-based tourism at Cotijuba Island - PA
}

\section{La posible actuación del Ecomuseo de la Amazonia en el desarrollo del turismo de base comunitaria en la Isla de Cotijuba - PA}

\author{
João Gabriel Pinheiro Huffner \\ Professor do Curso de Turismo da Faculdade Pan Amazônica \\ Mestre em desenvolvimento e Meio Ambiente Urbano pela Universidade da Amazônia - Unama \\ pinheirohuffner@yahoo.com.br \\ Maria Terezinha Resende Martins \\ Coordenadora do Ecomuseu da Amazônia/Funbosque \\ Doutora em gestão Integrada de Recursos Naturais pela Universidade Católica de Brasília -UCB \\ mtrmartins@gmail.com
}

Márcia Sueli Castelo Branco Bastos

Técnica da Secretária de Estado de Meio Ambiente e Sustentabilidade do Pará - Semas

Mestre em Gestão de Recursos Naturais e Desenvolvimento Local da Amazônia (PPGEDAM/NUMA/UFPA) marciasueli.pesquisa@gmail.com

Data de Submissão: 27/02/2017 - Data de Aceitação: 11/12/2017

\begin{abstract}
Resumo: As consequências das ações humanas sobre o meio ecológico e seus reflexos sociais e culturais estão em voga nas diferentes esferas de discussão, fazendo com que os modelos de desenvolvimento sejam repensados a partir da inserção de atividades com ênfase em princípios sustentáveis, como o turismo de base comunitária. Neste contexto, este artigo tem como objetivo central discutir a atuação do Ecomuseu da Amazônia como agente de desenvolvimento territorial sustentável, no fomento ao turismo de base comunitária nas comunidades da Fazendinha e do Poção, pertencentes à Ilha de Cotijuba, região metropolitana de Belém-PA. A metodologia adotada partiu da coleta de dados primários, secundários e pesquisas de campo, os quais permitiram a análise qualitativa da questão, caracterizando este como um estudo de caso exploratório e descritivo. As informações obtidas apontam para a possibilidade de execução das ações do Ecomuseu da Amazônia na estruturação, na participação, na capacitação e no empoderamento comunitário em torno do desenvolvimento do turismo sustentável local.
\end{abstract}


Palavras-chave: Ecomuseu da Amazônia, Sustentabilidade, Turismo de Base Comunitária.

Abstract: The consequences of human actions on the ecological environment, and their social and cultural repercussions, are currently at the forefront of the different spheres of discussion, prompting a rethinking of the former development models through the insertion of activities that emphasize sustainable principles, such as community-based tourism. In this context, this article discusses the role of the Amazon Ecomuseum as an agent of sustainable territorial development in the promotion of community-based tourism in the communities of Fazendinha and Poção, on the island of Cotijuba, a metropolitan region of Belém, Paraná. The methodology adopted was based on the collection of primary, secondary and field data, which allowed qualitative analysis of the question, characterizing this as an exploratory and descriptive case study. The information obtained points to the possibility of implementing the actions of the Amazon Ecomuseum in the structuring, participation, training and empowering of communities around the development of local sustainable tourism.

Keywords: Amazon Ecomuseum, Sustainability, Community-Based Tourism.

Resumen: Las consecuencias de las acciones humanas sobre el medio ecológico, y sus reflejos sociales y culturales están en boga en las diferentes esferas de discusión, haciendo que los modelos de desarrollo sean repensados a partir de la inserción de actividades con énfasis en principios sostenibles, como el turismo de base comunitaria. En este contexto, este artículo tiene como objetivo central discutir la actuación del Ecomuseo de la Amazonía como agente de desarrollo territorial sostenible, en el fomento al turismo de base comunitaria en las comunidades de Fazendinha y Poção, pertenecientes a la Isla de Cotijuba, región metropolitana de Belém-PA. La metodología adoptada partió de la recolección de datos primarios, secundarios e investigaciones de campo, los cuales permitieron el análisis cualitativo de la cuestión, caracterizando éste como un estudio de caso exploratorio y descriptivo. Las informaciones obtenidas apuntan a la posibilidad de ejecución de las acciones del Ecomuseo de la Amazonia en la estructuración, participación, capacitación y empoderamiento comunitario en torno al desarrollo del turismo sostenible local.

Palabras clave: Ecomuseo de la Amazonía, sostenibilidad, turismo basado en la comunidad.

\section{Introdução}

A preocupação socioambiental surge a partir do momento em que o homem toma consciência dos efeitos de suas ações sobre os recursos naturais e, consequentemente, sobre sua própria qualidade de vida. Segundo Andrade (2010), nas últimas décadas os debates sobre a questão ambiental têm sido alvo de preocupação e têm envolvido diferentes setores, como o político, o sociocultural e o ambiental. Os discursos ambientalistas estão presentes na academia, nos setores público e privado, assim como na sociedade civil. Têm sido abordados como projeto de desenvolvimento, porém contraditoriamente, os mesmos agentes públicos e privados não têm minimizado as práticas de degradação ambiental.

A população da Amazônia, no decorrer de sua história, tem sofrido consequências da exploração desordenada e consequente degradação ambiental, o que vem ocorrendo desde o período colonial até os dias atuais. As causas são diversas, destacandose o projeto desenvolvimentista adotado no país, seja com o Plano de Metas de Juscelino Kubichek (1956/1960), fortemente marcado pelo urbanismo contemporâneo e/ou pela política brasileira adotada até finais dos anos 1970, com os planos implantados pelos governos da Ditadura: Plano Nacional de Desenvolvimento Econômico (PND) e Plano de Integração Nacional (PIN), de 1964-1985, como a construção da transamazônica, dentre outros, e o que teóricos denominam de "Grandes Projetos" na Amazônia, sem qualquer preocupação com a sustentabilidade na região. Sem contar que, até meados do século XX, o Brasil ainda era um país de economia agroexportadora, com a maioria da população vivendo na zona rural (ANDRADE, 2010).

Evidencia-se que, gradualmente, o desenvolvimentismo perde a legitimidade, sendo alterado para o conceito de desenvolvimento sustentável, cujas discussões têm se ampliado principalmente a partir de 1972, com a Conferência das Nações Unidas sobre Meio Ambiente Humano e, em 1973-1974, com a crise do petróleo. Para Fonseca (2007), esta mudança de paradigma é 
um processo lento e descontínuo; ele considera que, à medida que o desenvolvimento social é adotado como norma social, lucros simbólicos são concedidos aos que o apoiam e os que são contrários sofrem prejuízos. Nesse sentido, o conceito de desenvolvimento sustentável, fruto do auge dos movimentos ambientalistas das décadas de 1970, 1980 e estabelecido em 1990 após a publicação do relatório Brundtland em 1987, surge da necessidade de galgar uma nova realidade para a forma como a humanidade se desenvolve, interagindo com o meio em que vive e utilizando seus recursos. Ainda segundo Fonseca (op.cit), faz-se necessária a incorporação das ideologias ambientalistas na ética individual. A incorporação da ideologia ambientalista é um processo em longo prazo, que necessita de educação e conscientização e sensibilização ecológica. Em seus princípios básicos, o desenvolvimento sustentável considera a busca do equilíbrio entre três elementos principais: a eficiência econômica, a proteção e restauração dos sistemas ecológicos e o bemestar de pessoas. Assim, é necessário conceber o desenvolvimento das sociedades e do meio ambiente saudáveis; zelar pela justiça na economia e nas questões sociais; e buscar a prudência no uso de recursos naturais na expansão econômica.

Compreende-se que o estado do desenvolvimento estabelecido gera consequências sociais e ambientais, reflexos do nível acelerado de industrialização que os países desenvolvidos, e em desenvolvimento, estão passando, da globalização da economia, da busca por novas fontes de recursos no campo energético, e questionamentos a respeito do consumismo exacerbado promovido em prol da manutenção da economia capitalista (HUFFNER, 2013). Desta forma, principalmente nos últimos quinze anos, o debate ambientalista ganhou novos contornos e novos paradigmas, reformulando conceitos, abordagens, técnicas, possibilidades de projetos urbanos, caminhando para uma ciência da síntese, que é a base da ecologia (VALLADARES, 2009).

Entende-se desta forma que todo conceito oriundo dos avanços nas discussões que envolvem os problemas socioambientais globais ainda estão em construção, concebendo um corpo teórico, porém com uma prática ainda limitada. Existe um longo caminho a ser trilhado, tanto no meio científico, quanto governamental e social, seja no cerne do desenvolvimento socioeconômico, e nas questões ambientais e culturais.
Voltados à preocupação com a sustentabilidade socioambiental surgem neste contexto os ecomuseus, que emergem da dialética entre as novas correntes museológicas e os movimentos preservacionistas socioambientais do século passado. São produto da nova museologia, como via de intervenção social, política, cultural e ambiental, contribuindo para o desenvolvimento humano, com respeito ao patrimônio natural e cultural a partir de ações voltadas à sua valorização e preservação.

Existem inúmeras concepções para o que vem a ser um "ecomuseu", dentre elas se destaca a definição de Pereiro (2002, p.6), "o Ecomuseu é um instrumento participativo e de ordenamento territorial, pois, permite a autogestão sustentável do patrimônio natural e cultural das comunidades". Para Martins (2010, p.32), é “a delimitação de um território que mostra o acervo natural e cultural de uma região $[. .$.$] integrando o ser vivo e o seu habitat".$ Destarte, este estudo tem por objetivo central discutir a atuação do Ecomuseu da Amazônia enquanto agente de desenvolvimento territorial sustentável, no fomento ao Turismo de Base Comunitária, nas comunidades da Fazendinha e do Poção, pertencentes à Ilha de Cotijuba em Belém do Pará. Para o alcance deste objetivo, foi realizada análise documental e visitas in loco nas comunidades envolvidas, objetivando conhecer os passos dados na realização do projeto de turismo de base comunitária e seus objetivos, que resultam na proposição aqui apresentada.

\section{O Ecomuseu da Amazônia: origem e conceito}

O Ecomuseu da Amazônia é um programa vinculado à Fundação Centro de Referência em Educação Ambiental - Escola Bosque Professor Eidorfe Moreira da Prefeitura Municipal de Belém. O programa atua por meio de projetos desde 2007 na região insular de Belém, principalmente nas ilhas de Caratateua, Mosqueiro e Cotijuba, com ações que visam ao desenvolvimento local com base na sustentabilidade socioambiental e na valorização cultural, contribuindo para a fixação do homem em sua terra. Surge como uma proposta que enfatiza a museologia social difundida na França nos anos de 1970/1980, sendo fundamentado no movimento dos museus ao ar livre, da redescoberta patrimonial no Reino Unido e na gênese do ambientalismo na museologia (MARTINS, 2010). 
Diferentemente dos museus tradicionais, o Ecomuseu da Amazônia segue a metodologia dos demais ecomuseus brasileiros e da Europa, pois não se limita a um espaço físico construído com acervo em exposição. É um museu território, cujo acervo é composto pelo ambiente natural e cultural local e pelos saberes e fazeres populares das comunidades tradicionais amazônicas.

O termo "ecomuseu", de origem francesa, surge na década de 1970, difundido por Hugues de Varine, que segundo Pereiro (2002), pode ser entendido como um instrumento de integração e participação social, com vistas ao ordenamento e ao gerenciamento territorial a partir da valorização dos aspectos culturais oriundos do saber e do fazer do homem, e do patrimônio natural.

Neste contexto, o Ecomuseu da Amazônia, em sua essência, pode ser entendido como um instrumento de gestão territorial que visa à sustentabilidade ambiental, social e cultural das comunidades das ilhas de Belém por meio do fomento, da valorização, da difusão e do respeito às tradições, às atividades artesanais, artísticas e o saber do homem amazônico no uso sustentável dos recursos naturais para sua sobrevivência.

As ações desenvolvidas pelo Ecomuseu da Amazônia estão fundamentadas em um programa de capacitação dos atores do desenvolvimento local, que por sua vez é executado por meio de eixos temáticos, a saber: os eixos cultura, cidadania, meio ambiente e turismo de base comunitária.

A metodologia de eixos temáticos é desenvolvida de forma integrada a partir de projetos distintos. Os projetos atualmente desenvolvidos são de agricultura familiar sustentável, piscicultura sustentável, biomapas, calendário de frutas, apoio ao artesanato e às manifestações culturais nas ilhas, e turismo de base comunitária nas comunidades da ilha de Cotijuba.

\section{A Ilha de Cotijuba, o turismo e as suas interfaces com a ocupação do território}

A ilha de Cotijuba faz parte do estuário Amazônico. Limita-se ao Norte pela baía de Marajó; ao Sul pelo furo do Mamão, que a separa das ilhas de Jutuba e Paquetá; a Leste pela ilha de Tatuoca; e a Oeste pelo canal de Cotijuba. Situase a uma distância de $9 \mathrm{~km}$ do distrito de Icoaraci, e a $33 \mathrm{~km}$ do centro de Belém. Seu território se estende por uma área de aproximadamente 60 $\mathrm{Km}^{2}$ com uma costa de $15 \mathrm{~km}$ de praias de água doce (MARTINS, 2003) (Figura 1).

Cotijuba detém a terceira posição em tamanho e densidade demográfica entre as mais

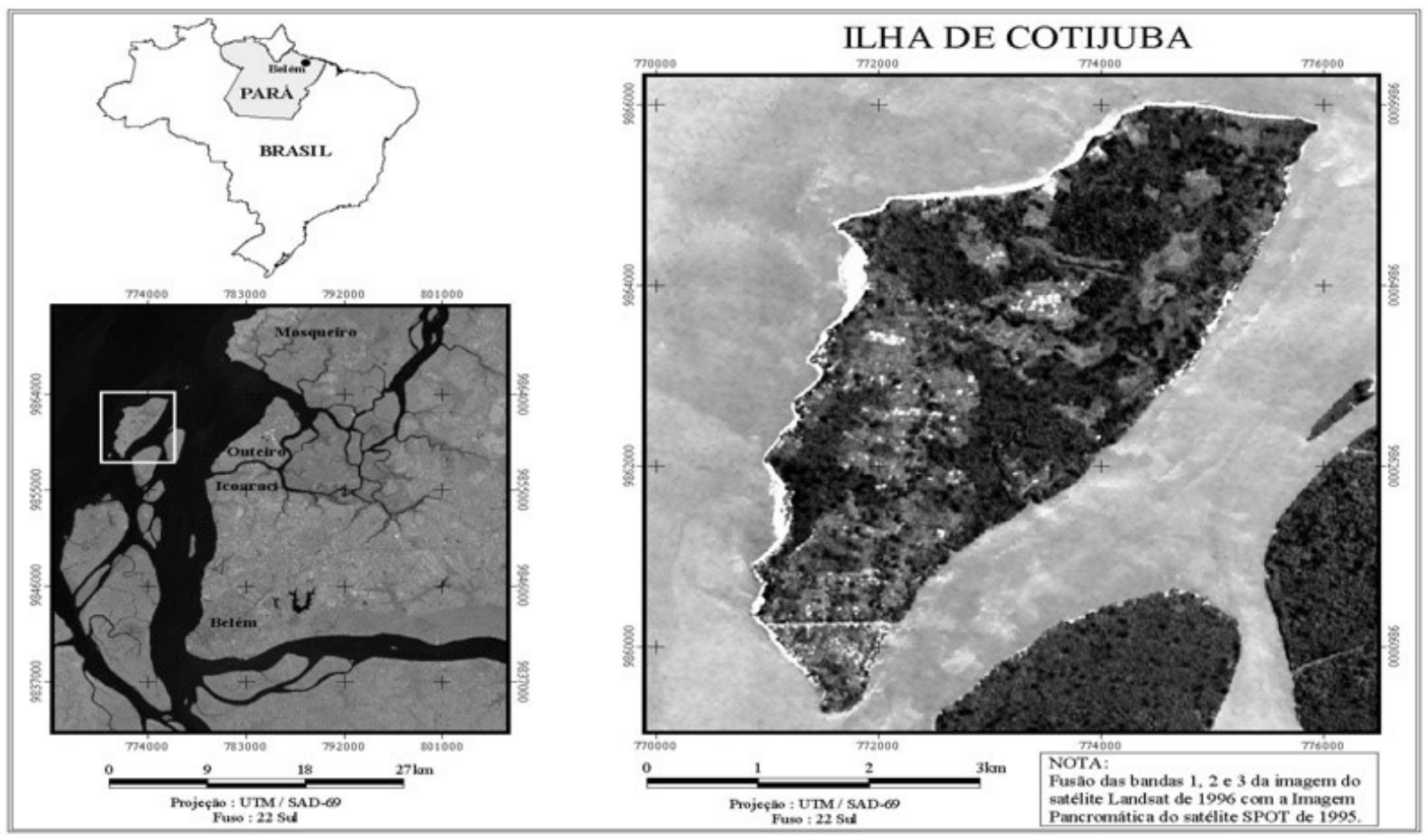

Figura 1: Mapa da Ilha de Cotijuba.

Fonte: Museu Goeldi - MPEG (2009). 
de 30 ilhas pertencentes ao entorno da cidade de Belém (GUERRA, 2007). No entanto, os dados sobre o número de habitantes na ilha de Cotijuba são confusos e escassos até mesmo nas pesquisas realizadas pelo Instituto Brasileiro de Geografia e Estatísticas (IBGE).

Atualmente, segundo dados não oficiais provenientes da Agência Administrativa do Outeiro (AROUT), Cotijuba conta com um número de aproximadamente 9.000 habitantes fixos e nos períodos de férias escolares e feriados, a ilha chega a receber cerca de 20.000 visitantes por fim de semana (BELEMTUR, 1998).

A ilha de Cotijuba se encontra sob jurisdição administrativa da prefeitura municipal de Belém e integra o Distrito Administrativo do Outeiro.

Em 1990 Cotijuba foi alvo de proposta para transformação em uma Área de Proteção Ambiental, mais especificamente em uma Área de Relevante Interesse Ecológico, fato não confirmado por meio de ato legislativo.

Os ambientes insulares sempre foram alvo de interesse da população vivente nas cidades como locais propícios ao descanso e ao lazer. Diegues (1997, p.3) enfatiza que:

No Brasil, assim como em outras partes do mundo, as imagens das ilhas tropicais invadiram os meios de comunicação como últimos redutos do mundo selvagem, lugares paradisíacos para novas descobertas, aventuras e lazer tranquilo.

Este imaginário descrito como ambiente calmo e natural é o que impulsiona o turismo na ilha.

Cotijuba há décadas serve como local de lazer e recreação para os moradores de Belém e vizinhanças. Levantamentos realizados pela Superintendência Executiva de Mobilidade Urbana de Belém (SEMOB) registram cerca de 17 mil passageiros ao mês na baixa temporada, e 50 mil durante a alta temporada. Esses registros referem-se aos passageiros que utilizam o transporte oferecido pela prefeitura de Belém, sem contabilizar as viagens em embarcações de terceiros ou particulares. Com isso supõe-se que a estimativa real ultrapasse os dados oficiais, caracterizando o turismo de massa (HUFFNER; BELLO, 2013).

O espaço produzido pelo turismo em Cotijuba sempre foi envolto no discurso "ecológico" manipulado pela lógica do mercado turístico capitalista, com escassas propostas de planejamento e ordenamento da atividade, o que contribuiu para a periferização da ilha e o avanço do modo de vida urbano caracterizado pela precariedade estrutural e social.

Cabe salientar que "a prática social do turismo acaba por recriar o urbano em locais inicialmente escolhidos por não o serem" (CRUZ, 2007, p.104), como é claramente percebido em seu território.

Há pelo menos duas décadas a ilha apresentava uma organização socioeconômica e territorial baseada na agricultura, na pesca e na pecuária de subsistência, longe da realidade urbana que hoje avança sobre seu território. Durante anos apenas agricultores, pescadores e ex-presidiários oriundos da casa penal que ali existiu viviam em Cotijuba. Tais fatos caracterizam o ambiente inóspito e exótico que prevaleceu na ilha sem grandes intervenções humanas sobre seu ambiente natural.

A ocupação urbana recente da ilha constitui uma consequência do crescimento demográfico e urbano de Belém rumo às áreas mais distantes, pois, com o encarecimento da terra próxima aos núcleos centrais, ocorre a periferização urbana, que se acentua com a falta de políticas integradas e ações articuladas de gestão territorial.

Atualmente a população local espelha o reflexo do processo de urbanização recente no local, formada por moradores antigos pertencentes às famílias de ex-presidiários, primeiros invasores oriundos das periferias de Belém e o grupo mais recente, os que chegam à Ilha desde a implantação da energia elétrica em 2005 (SILVA, 2010).

Com a inserção do turismo na economia local, outras atividades antes predominantes ficaram restritas às áreas mais distantes, tais como o plantio de frutas e hortaliças localizados na região norte da ilha, pois o turismo dinamizou a ocupação e o uso do solo em toda a ponta sul.

Silva (2010) acrescenta que, a partir da descoberta de Cotijuba para o turismo, muitos habitantes passaram a viver da venda de alimentos, prestação de serviços e demais atividades direcionadas ao atendimento do visitante, em busca de renda e melhor qualidade de vida. Este autor explica que a mais profunda mudança foi alcançada com a implantação da linha fluvial pela prefeitura em 1994, contribuindo para a ocupação desordenada nesse território que, aliado à falta de planejamento e de políticas públicas, a invasão de áreas protegidas, a especulação imobiliária e 
o crescimento demográfico contribuíram para a existência de um turismo massificado na ilha.

O turismo de massa tem contribuído significativamente para a reconfiguração territorial local, fazendo com que novas paisagens surjam com um forte toque de antropismo, paisagens estas profundamente marcadas por transformações na infraestrutura e no modo de vida das pessoas que habitam a ilha, tornando-a de certa forma parte da periferia de Belém (MELO, 2008).

Surge assim a necessidade latente de promover o desenvolvimento de segmentos e práticas turísticas que busquem a sustentabilidade socioambiental e cultural, promovendo o bemestar das comunidades que habitam a ilha. Nesse contexto, descortina-se o Turismo de Base Comunitária (TBC), entendido como possibilidade de fomento ao desenvolvimento local socioambiental sustentável.

OTBCestápautadonos preceitos enos princípios de sustentabilidade econômica, social e ambiental e com novos modelos de gestão da atividade. É considerado por autores como Swingerlust (2002) como um tipo de turismo alternativo e sustentável. No entanto existem diversas categorias de turismo sustentável ou alternativo, e o TBC se diferencia das demais por ter a comunidade como objeto central do desenvolvimento.

\section{As comunidades fazendinha e poção: possibilidades para o turismo de base comunitária}

Para melhor compreensão acerca do significado do termo comunidade como categoria de discussão, utilizou-se neste texto o conceito difundido por Wagley (1954), que entende comunidade como uma unidade populacional heterogênea, porém estruturada em valores, símbolos, crenças, hábitos, economia e religião, organizada e que dispõe de uma hierarquia na qual o indivíduo se insere.

A ilha de Cotijuba possui doze comunidades: Praia da Saudade, Faveira, Flexeira, Praia Funda, Quatro Bocas, Canivete, Seringal, Pedra Branca, Vai-Quem-Quer, Farol, Poção e Fazendinha (Figura 2) (SILVA, 2010).

Apesar do avanço da ocupação urbana influenciada pela intensificação do comércio, serviços e turismo de massa, Cotijuba ainda

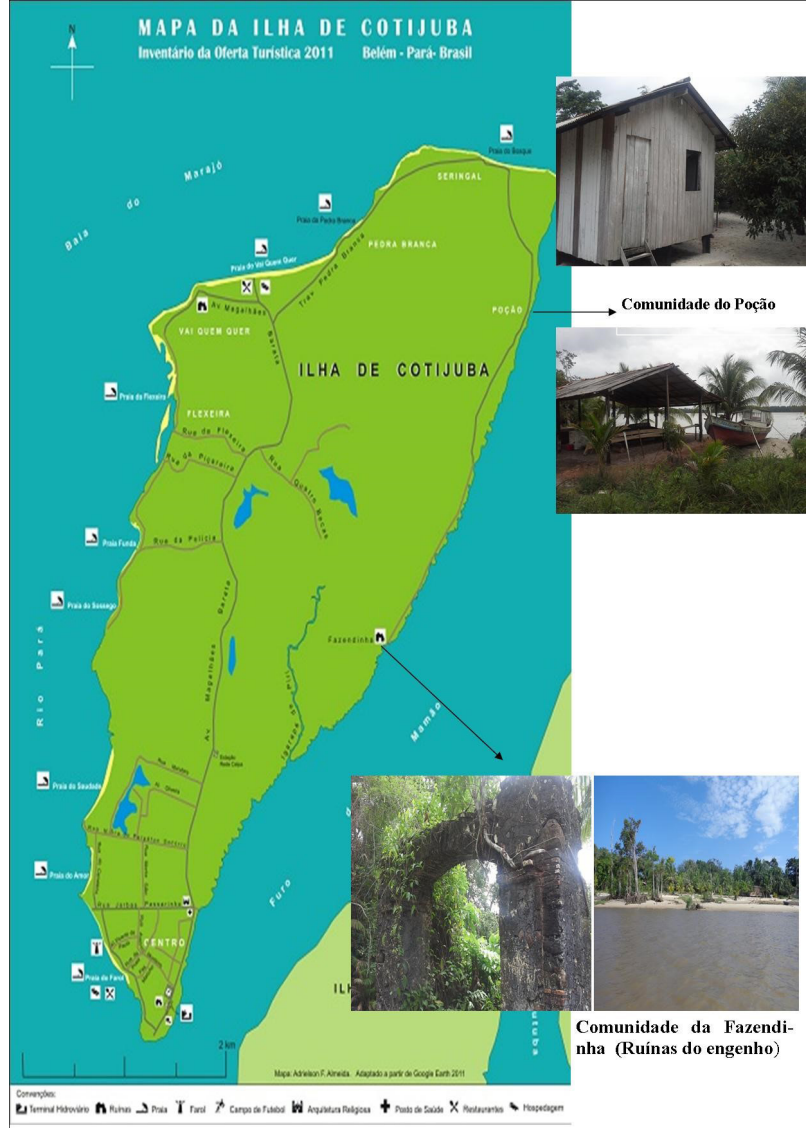

Figura 2: Localização das comunidades Poção e Fazendinha

Fonte: Belemtur (2011).

possui localidades que vivem das atividades agrícolas/extrativistas, e em um ambiente natural ainda preservado, a exemplo das comunidades Fazendinha e Poção. Tais comunidades estão localizadas na região leste da ilha de Cotijuba, a cerca de $18 \mathrm{~km}$ de distância do trapiche central. Possuem certo grau de isolamento devido a distância do núcleo central da ilha e às dificuldades de acesso, pois só é possível chegar por barcos fretados ou via terrestre a partir do centro de Cotijuba, em estrada de terra batida.

Ocontingentepopulacionaldasduascomunidades é pequeno, cerca de duzentos moradores, o qual é formado principalmente por pequenos agricultores, artesãos, extrativistas e pescadores (ECOMUSEU DA AMAZÔNIA, 2016).

Em pesquisa realizada pelo Ecomuseu da Amazônia/Funbosque (2016), foram obtidos indicadores do perfil socioeconômico dos moradores locais. Segundo os resultados da pesquisa, $80 \%$ deles recebem apoio financeiro de programas sociais e $90 \%$ possuem renda mensal média de apenas um salário mínimo. 
A comunidade da Fazendinha tem sua origem ligada à construção de um engenho de embranquecimento de arroz, denominado Engenho da Fazendinha, onde existia uma pequena fazenda pertencente ao então Capitão Pereira da Cunha (GUERRA, 2007).

$O$ Engenho da Fazendinha foi erguido em 1784. Atualmente, no local, permanecem as ruínas do engenho às margens do Igarapé do Ladrão (Figuras 3 e 4).

O engenho da Fazendinha, construído em 1784, foi posteriormente sendo ocupado por ribeirinhos oriundos de várias partes da região e pertenceu a um período estratégico de ocupação da Ilha de Cotijuba (MELO, 2008).

A comunidade do Poção é contigua à Fazendinha, também localizada na região leste da ilha de Cotijuba, próxima à comunidade da Pedra Branca. O perfil socioeconômico dos moradores é similar ao dos habitantes da Fazendinha, em sua maioriapescadores, artesãose pequenos agricultores. As famílias recebem auxílio de programas sociais governamentais para complementar a renda, que não ultrapassa um salário mínimo (ECOMUSEU DA AMAZÔNIA, 2016).

A atratividade local gira em torno do patrimônio cultural (material e imaterial) constituído pelos saberes e fazeres dos comunitários e as ruínas do engenho, assim como do ambiente natural,

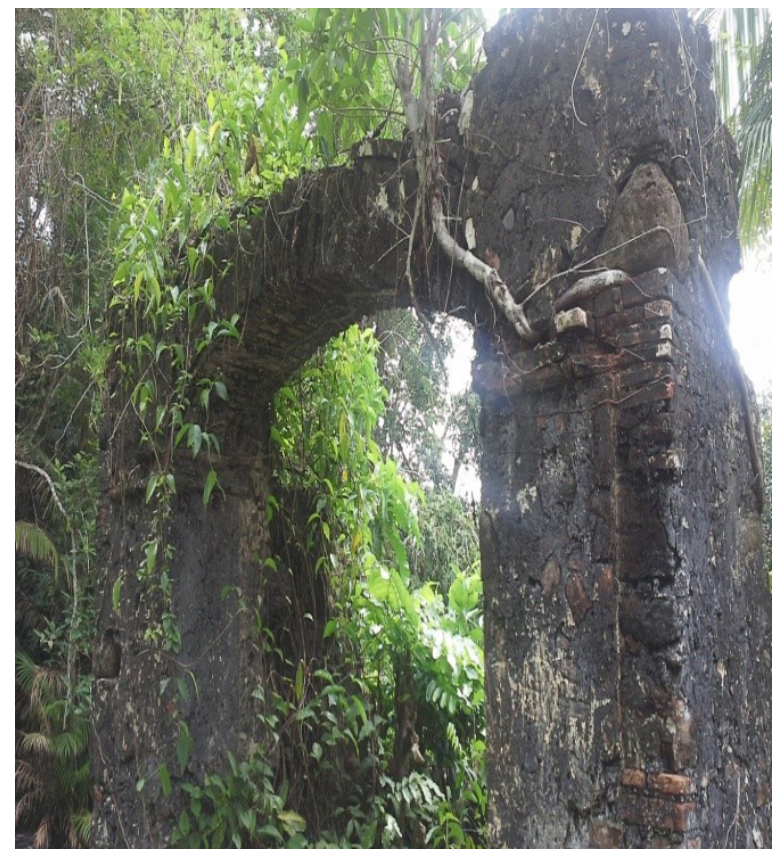

com belas praias e trilhas cercadas por vegetação nativa. Neste contexto, surge a possibilidade de pensar a implantação de novas atividades econômicas pautadas em princípios sustentáveis com o objetivo de contribuir para a melhoria da qualidade de vida da população local, bem como para salvaguarda do patrimônio local.

A partir do potencial identificado nas comunidades, percebe-se o Turismo de Base Comunitária como importante ferramenta capaz de valorização do potencial turístico do lugar, como a gastronomia, a religiosidade e as demais manifestações culturais, a exemplo das atividades extrativistas sustentáveis e da produção artesanal.

O Turismo de Base Comunitária (TBC) é entendido como alternativa passível de desenvolvimento nas comunidades da Fazendinha e Poção, não como um segmento turístico, mas como uma metodologia de desenvolvimento do turismo, cuja comunidade passa a ser protagonista na condução da atividade. De acordo com Coriolano (2009),

[...] o turismo comunitário é aquele em que as comunidades de forma associativa organizam arranjos produtivos locais, possuindo o controle efetivo das terras e das atividades econômicas associadas à exploração do turismo. Nele o turista é levado a interagir com o lugar e com as famílias residentes, seja de pescadores,

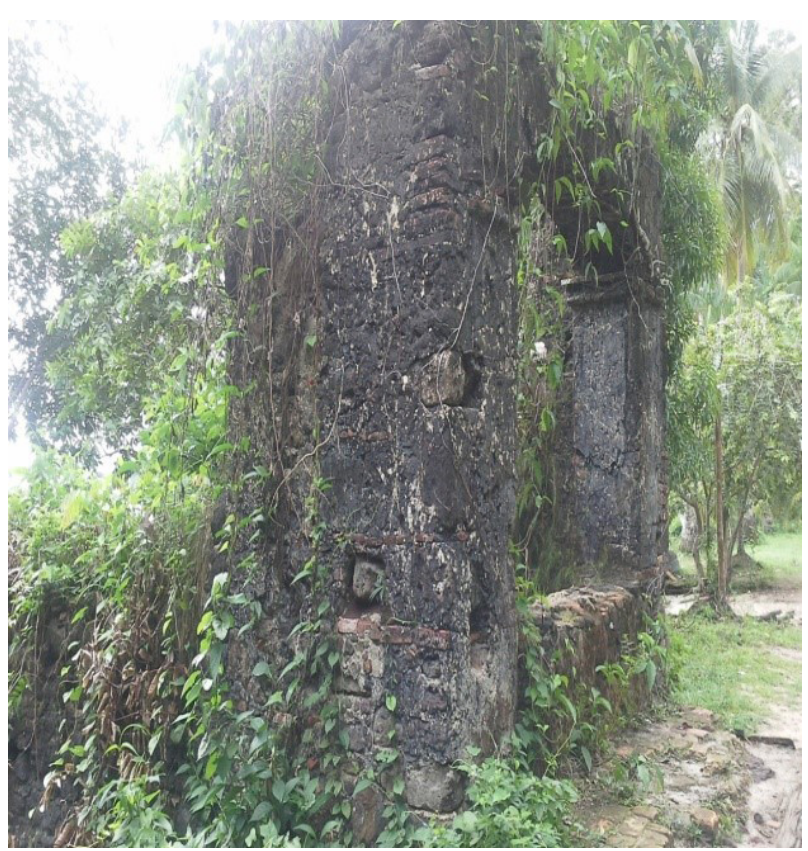

Figuras 3 e 4: Ruínas do Engenho da Fazendinha Fonte: Huffner (2016). 
ribeirinhos, pantaneiros ou de índios. (CORIOLANO, 2009, p. 282).

Portanto, busca-se a permanência de todo o conjunto de bens patrimoniais próprios da localidade. Procurando meios de mostrar como o ambiente natural, a história, a tradição e a cultura local, além de apreciadas pelas suas belezas, podem ser vetores de incremento do trabalho e da comercialização para ganhos financeiros dos residentes.

O Ecomuseu da Amazônia surge neste cenário como articulador técnico para a viabilização do processo de organização social comunitária, sensibilização e capacitação.

O projeto de turismo de base comunitária proposto pelo Ecomuseu da Amazônia tem como fundamento central o elo entre as perspectivas socioeconômicas e ambientais de desenvolvimento sustentável e a valorização do patrimônio cultural material e imaterial das comunidades da ilha de Cotijuba.

Portanto, pensar o TBC com as comunidades da Fazendinha e Poção como protagonistas do projeto vai além do aproveitamento do patrimônio local e seus atrativos, pois se trata do fortalecimento comunitário em defesa do território, da afirmação identitária e da sensibilização para a valorização e para a salvaguarda dos conhecimentos tradicionais, da história, da cultura, dos saberes e fazeres e do patrimônio natural, ou seja, o turismo de base comunitária é um instrumento de luta e resistência social a serviço da comunidade.

\section{Procedimentos metodológicos}

Para alcance do objetivo central, a metodologia empregada partiu de uma abordagem participativa, descritiva e exploratória, perpassando o levantamento de dados secundários, como artigos científicos, relatórios e documentos oficiais do Ecomuseu, tendo a finalidade de proceder à reunião de informações subsidiando o conhecimento relativo ao objeto de investigação.

O trabalho aconteceu em fases distintas, tendo como base fundamental a pesquisa bibliográfica, que segundo Lakatos (2003, p.158), se caracteriza como "um apanhado geral sobre os principais trabalhos já realizados, revestidos de importância, por serem capazes de fornecer dados atuais e relevantes relacionados com o tema”. Em seguida foi realizada pesquisa documental, com a formatação de um arcabouço constituído de dados históricos oficiais, bibliográficos, informações, pesquisas e material cartográfico; arquivos oficiais, e registros em geral.

A partir das informações coletadas, optouse por uma abordagem investigativa de base qualitativa para a fase seguinte. De acordo com Lima (2011, p.8), "a pesquisa qualitativa permite uma compreensão dos fenômenos estudados, através da atenção aos detalhes e do conhecimento sobre situações específicas". Neste caso, a pesquisa se caracteriza como qualitativa por explorar aspectos subjetivos de análise dos dados e do local de estudo. Esse trabalho se enquadra especificamente como um estudo de caso, tendo o Ecomuseu da Amazônia como unidade de análise.

Yin (2011) considera que o estudo de caso se caracteriza pela coleta dos dados sobre determinada área, objeto ou situação a partir de variadas fontes, como documentos oficiais, livros, estudos, pesquisas e investigações in loco. Deslandes e Minayo (2011) classificam a categoria estudo de caso como um tipo de pesquisa de cunho exploratório e descritivo, que visa aumentar o entendimento sobre fenômenos sociais complexos.

Procedeu-se ao levantamento dos dados obtidos com a análise de documentos, livros, pesquisas e relatórios, que apresentam dados diretos ou indiretos sobre o desenvolvimento das ações do Ecomuseu da Amazônia, buscando construir um parâmetro analítico específico.

Desta forma, o processo metodológico culminou na interpretação dos dados e na compilação sistemática das informações obtidas, traçando por fim um panorama acerca do objeto de estudo, possibilitando a discussão sobre os possíveis entraves ou gargalos para o efetivo avanço nas ações engendradas pelo Ecomuseu da Amazônia como instrumento de gestão e fortalecimento socioambiental e econômico endógeno na região insular de Belém.

\section{O Projeto de TBC do Ecomuseu da Amazônia nas comunidades da Fazendinha e do Poção}

O Ecomuseu da Amazônia sustenta-se em quatro eixos de atuação, a saber: turismo de base comunitária, cultura, meio ambiente e cidadania. 
Nesses eixos são desenvolvidos projetos conduzidos por técnicos com formação acadêmica e experiência profissional nos seus respectivos temas. Os técnicos responsáveis por cada eixo elaboram projetos que possuem um aspecto medular em comum: a busca pela sustentabilidade socioambiental e autonomia das comunidades na gestão de seus territórios e do patrimônio natural e cultural.

O turismo de base comunitária surge como eixo estruturante do Ecomuseu da Amazônia a partir das demandas oriundas das próprias comunidades da região insular de Belém em meados de 2007.

Foram realizadas reuniões mediadas pelos técnicos do Ecomuseu da Amazônia, objetivando o levantamento do patrimônio, da realidade socioeconômica local e as alternativas de projetos a serem implantados.

Naquela ocasião ficou evidente a necessidade de se trabalhar de forma prática e teórica a integração "patrimônio e população" em um processo orgânico e cíclico, em que ressaltar o patrimônio pode ser uma forma de dinamizar a comunidade (MARTINS, 2010).

O início do processo de planejamento para o desenvolvimento do turismo de base comunitária na região insular de Belém, capitaneado pelo Ecomuseu da Amazônia, se deu a partir da percepção das demandas e das possibilidades de projetos a serem implantados, e que consistiu na inventariação patrimonial das comunidades e do seu território. A identificação do patrimônio foi feita de forma participativa, tendo como metodologia a elaboração de biomapas, que são representações gráficas/ artísticas contendo o patrimônio preconizado e valorizado pela comunidade.

Esse processo envolveu, além da Ilha de Cotijuba, várias comunidades oriundas das áreas de atuação do Ecomuseu da Amazônia nas ilhas de Caratateua, Mosqueiro, Jutuba e em Icoaraci. Na ilha de Cotijuba, as comunidades da Fazendinha e do Poção se destacaram como detentoras de rico patrimônio cultural (material e imaterial) e natural propícios ao desenvolvimento do turismo de base comunitária.

De acordo com Benevides (2002), o turismo comunitário pode ser entendido como uma estratégia de desenvolvimento para populações tradicionais frente aos processos globalizantes hegemônicos, ao avanço do modo de vida urbanoconsumista e ao turismo de massa, o que requer um planejamento holístico que contemple cinco aspectos fundamentais; preservação ambiental, manutenção e valorização da identidade cultural, geração de novas ocupações e ampliação da renda, desenvolvimento colaborativo e participativo, e efetivas contribuições à qualidade de vida.

Partindo desse pressuposto e para subsidiar propostas visando ao aumento da autonomia das comunidades da Fazendinha e do Poção, o Ecomuseu da Amazônia elaborou um projeto pautado em quatro princípios norteadores, que são: o empoderamento e o pertencimento comunitário perante a atividade turística e o seu território; a capacitação para o TBC; a estruturação do destino, e a educação patrimonial e ambiental comunitária.

O projeto de turismo de base comunitária para a Fazendinha e Poção teve início a partir da realização de uma reunião de sensibilização da comunidade para apresentação da proposta. Por ocasião da reunião foram distribuídos convites às famílias da Fazendinha e do Poção, nos quais era informado o objetivo de desenvolver um projeto de turismo de base comunitária com foco na preservação ambiental e educação patrimonial.

Com o intuito de ilustrar casos de sucesso no âmbito do turismo de base comunitária no Pará, foi convidado para a reunião o Sr. Ivaldo Silva - Coordenador de Políticas para o Turismo da Secretaria de Estado de Turismo - SETUR (Figura 5), que explanou aos participantes o trabalho desenvolvido pela SETUR no apoio às iniciativas de TBC no Pará, assim como os desafios encontrados para efetivar um modelo de gestão eficiente e sustentável da atividade turística em comunidades tradicionais no Estado.

A apresentação do projeto culminou em sua aceitação perante as famílias presentes, que responderam por meio de questionário ter interesse em adotar o turismo de base comunitária como estratégia de desenvolvimento sustentável em suas múltiplas possibilidades.

Em síntese, o projeto a ser desenvolvido nas comunidades da Fazendinha e do Poção ficou estruturado nas seguintes etapas: inventário patrimonial; pesquisa do perfil socioeconômico da comunidade local e da produção associada ao turismo; ações de educação e valorização 


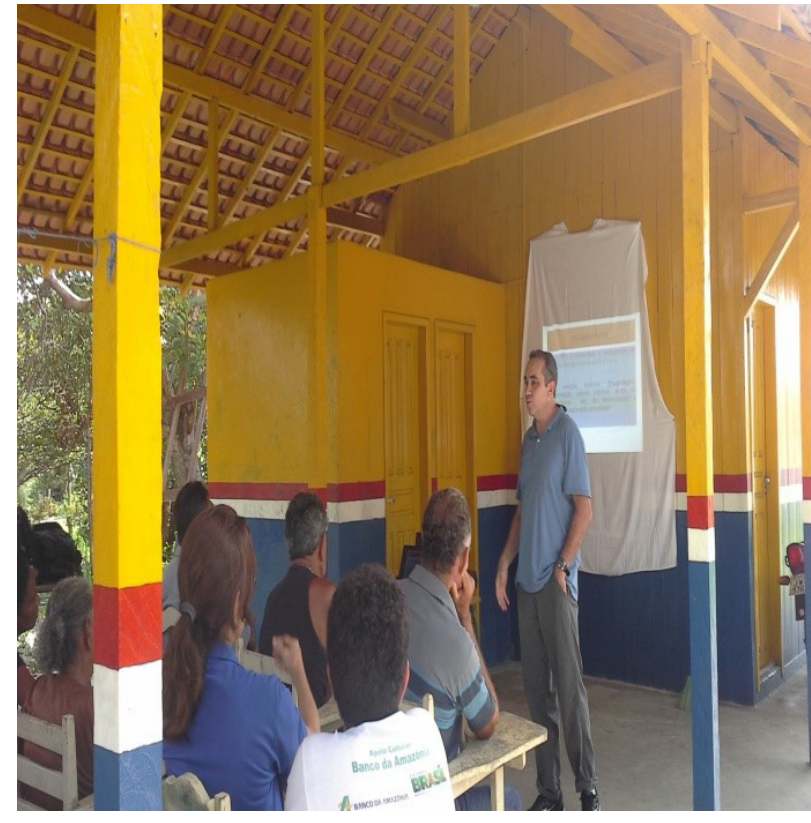

Figura 5: Reunião de apresentação do projeto de TBC à comunidade

Fonte: Huffner (2016).

cultural/ambiental; oficinas de bem receber, aprimoramento e comercialização do artesanato; formatação de serviços e roteiros; e reuniões periódicas participativas de gestão e avaliação.

O projeto visa estabelecer a cooperação e a gestão comunitária, articulando a formação da cadeia produtiva em torno de atrativos e serviços específicos, que tenham como base desde a estruturação dos atrativos turístico-culturais e qualificação dos serviços até a comercialização dos produtos ofertados.

O intuito é gerar um fluxo de visitantes que conheça o modo de vida da comunidade, consumindo produtos e serviços locais, contribuindo para estabelecer uma nova consciência entre os comunitários em prol da valorização do seu patrimônio ambiental e cultural.

Para o empoderamento da comunidade como representantes legítimos do patrimônio local, há necessidade de sensibilização, capacitação e organização social dos grupos comunitários, de forma que sejam protagonistas de todo o processo acerca do turismo sustentável como alternativa de desenvolvimento econômico e geração de benefícios coletivos. Nesse sentido, o Ecomuseu da Amazônia realizou oficinas de artesanato, com o objetivo de aprimorar e diversificar a produção mantendo as características locais, o que gerou grande entusiasmo entre os participantes para a comercialização dos produtos entre os visitantes.
Para a realização de cursos e oficinas, o Ecomuseu da Amazônia buscou ouvir as demandas locais, identificando suas oportunidades e carências, e realizou parceria com outros órgãos e entidades que promovem cursos e palestras, ofertando no ano de 2016 cursos de pertinentes com o objetivo de capacitar os atores locais para o turismo de base comunitária. Porém, existem as limitações inerentes a qualquer tipo de projeto ou proposta de planejamento. Limitações estas percebidas tanto pelos autores/proponentes da iniciativa quanto pela própria comunidade.

Analisar os fatores limitantes da proposta é tarefa imprescindível para que seja encontrado um meio termo entre a realidade e as ideias de "paraíso" propagadas ao associar as perspectivas de desenvolvimento à implantação do turismo.

De tal forma, uma das principais propostas para o TBC nas comunidades da Fazendinha e do Poção em Cotijuba é a formatação de um roteiro turístico contemplando cada atrativo cultural e natural, que foi denominado "Roteiro Patrimonial de Visitação", cuja base metodológica é o ordenamento de pontos de visitação turística em torno do patrimônio comunitário local e das atividades tradicionais desenvolvidas na comunidade, como a produção de farinha, a aquicultura sustentável, o artesanato em cerâmica e a artesania naval de barcos e canoas regionais.

\section{$O$ roteiro patrimonial de visitação}

O "Roteiro Patrimonial de Visitação" é parte integrante do projeto de Turismo de Base Comunitária idealizado pelo Ecomuseu da Amazônia para as comunidades da Fazendinha e do Poção na ilha de Cotijuba. O roteiro pontua o patrimônio natural e cultural existentes nas duas comunidades, os quais compõem a paisagem local como forma de valorização e conservação patrimonial, visando ao desenvolvimento sustentável das comunidades a serem visitadas. Portanto, o "Roteiro Patrimonial de Visitação" é uma das estratégias pensadas pelo Ecomuseu da Amazônia no sentido de fomentar o desenvolvimento endógeno sustentável, a fim de garantir a preservação e a valorização dos saberes e dos fazeres tradicionais das comunidades envolvidas, assim como do seu patrimônio natural e cultural, o qual serve como pano de fundo para o desenvolvimento do turismo de base comunitária. 
O roteiro está estruturado em 16 pontos de visitação, contemplando o patrimônio histórico, cultural e natural das comunidades, iniciando pelas ruínas do engenho da Fazendinha, passando pelas residências dos mestres barqueiros, artesãos, agricultores e piscicultores, em que em cada ponto é possível aprender sobre as atividades tradicionais exercidas na comunidade, experimentar a comida, conhecer o cultivo de peixes regionais e conhecer o artesanato local. O trabalho de formatação do roteiro foi feito em parceria com os próprios moradores, a partir da inventariação do patrimônio local, seguindo as etapas de identificação, descrição, marcação dos pontos com equipamento de GPS; elaboração do biomapa ilustrando os atrativos visitados (Figura 6); sinalização do roteiro, culminando na organização de uma viagem experimental, tendo a comunidade como ator principal.

Em maio de 2016 as comunidades do Poção e da Fazendinha, junto ao Ecomuseu da Amazônia, realizaram uma viagem experimental para testar o Roteiro Patrimonial de Visitação. Essa viagem contou com a participação de 25 pessoas e teve a duração de um dia. Na ocasião, os moradores se

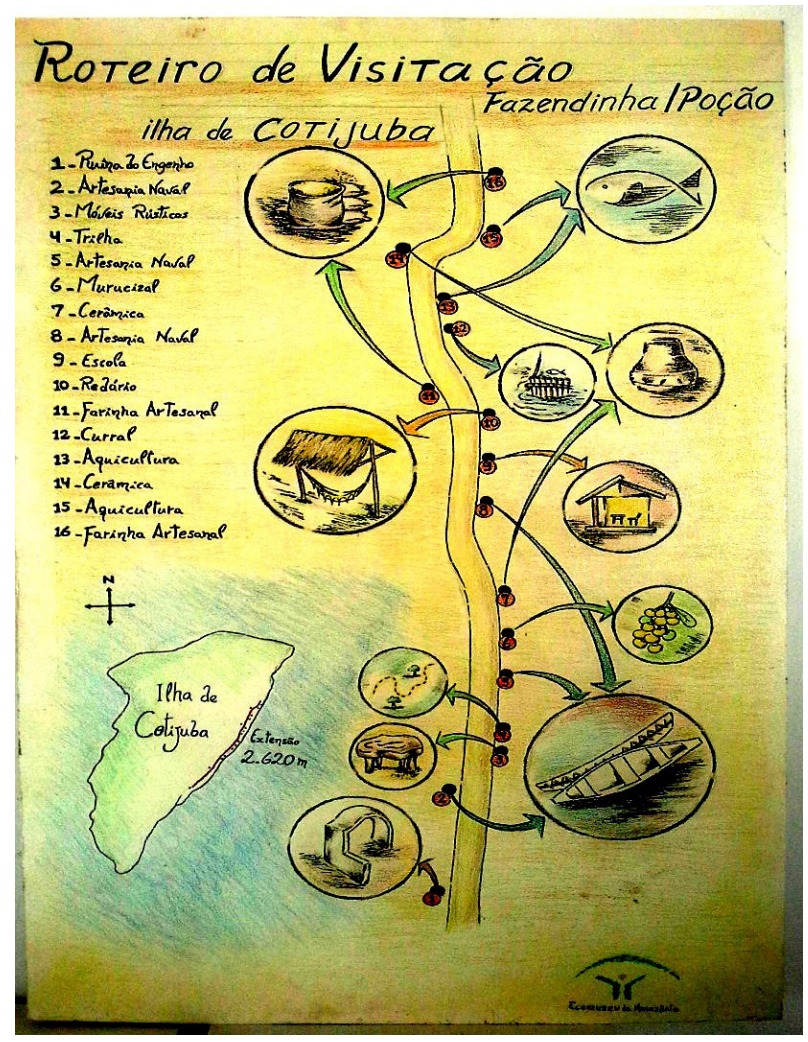

Figura 6: Biomapa ilustrando os atrativos do Roteiro Patrimonial de Visitação

Fonte: Ecomuseu da Amazônia (2016). envolveram na prestação de serviços relacionados à alimentação, ao transporte dos visitantes em embarcações próprias, à venda de artesanato e em diálogos sobre o patrimônio local e seus saberes e fazeres (Figuras 7 e 8 )

$O$ roteiro patrimonial de visitação surge como um dos produtos do projeto de turismo de base comunitária visando ao envolvimento e ao empoderamento comunitário, principalmente em relação às questões ambientais e patrimoniais, à organização e ao fortalecimento comunitário, e aos possíveis benefícios a partir da inserção do turismo como atividade socioeconômica. A proposição em questão considera a comunidade como agente principal no processo de ocupação, uso e manutenção do seu território. Nessa perspectiva, vale-se do trabalho desenvolvido pelo Ecomuseu da Amazônia como museu território dinâmico, em que a comunidade é a principal protagonista na conservação dos seus saberes e fazeres por meio de um acervo patrimonial a ser preservado.
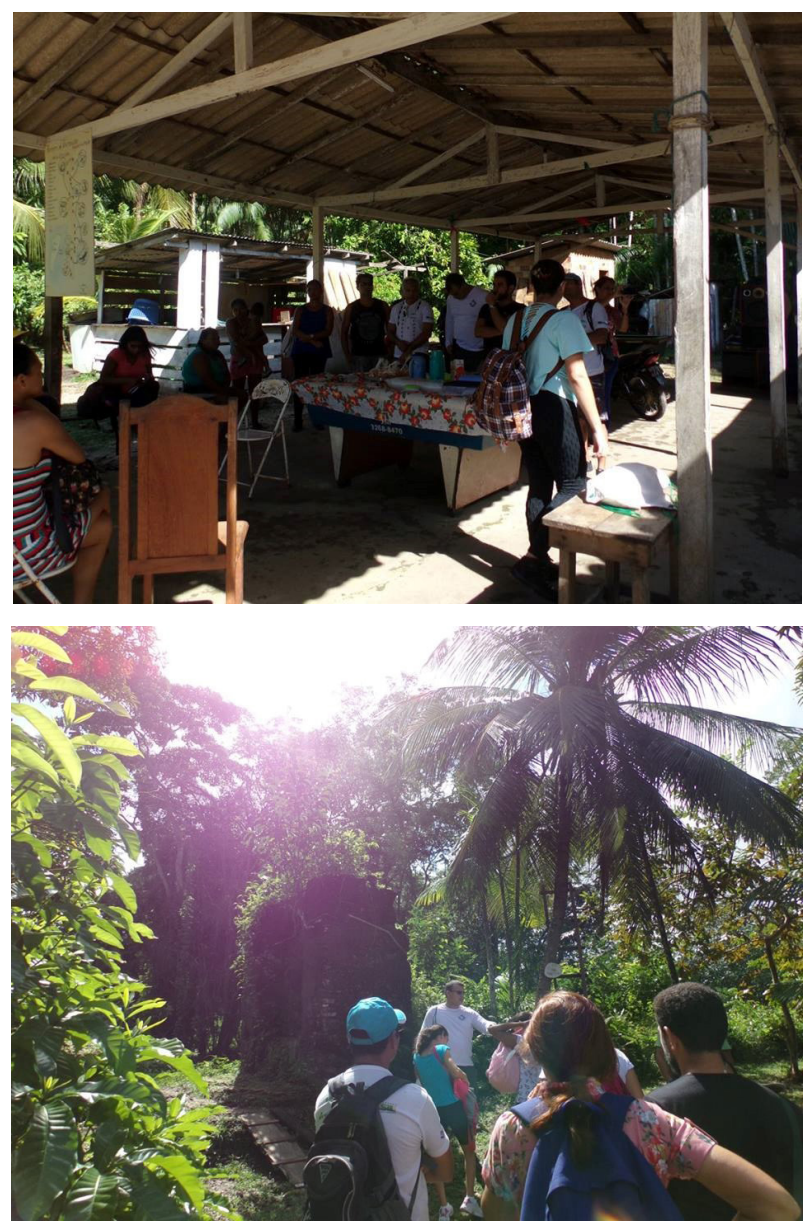

Figuras 7 e 8: Visitantes no Roteiro Patrimonial de Visitação - Fazendinha/Poção

Fonte: Bruna Sousa (2016). 
O projeto de turismo de base comunitária proposto pelo Ecomuseu da Amazônia não possui vínculos com a iniciativa privada, especificamente com operadoras e empresas que atuem na comercialização e no fomento ao TBC no Brasil e na Amazônia. No entanto, o elo entre comunidade e mercado deve ser estabelecido, pois, para atingir o público consumidor de roteiros e destinos de turismo de base comunitária, é necessária experiência e conhecimento para que se estabeleça um canal entre a comunidade e o público-alvo.

As possibilidades de fortalecimento de uma espécie de cadeia produtiva local do turismo de base comunitária nas comunidades da Fazendinha e do Poção são tantas quanto os desafios colocados à frente do projeto discutido neste estudo, pois, de um lado, existe o envolvimento comunitário coordenado pelo Ecomuseu da Amazônia e os atrativos históricos, culturais e naturais locais como ponto forte e, de outro, as limitações financeiras, estruturais e de apoio institucional para a consecução das ações e posterior alcance dos objetivos. Porém, o intuito é fazer com que as comunidades alcancem sua autonomia, absorvendo as possibilidades de incremento ao desenvolvimento local a partir do turismo de base comunitária.

\section{Considerações finais}

A proposta central deste estudo foi analisar as ações de desenvolvimento do Turismo de Base Comunitária engendradas pelo Ecomuseu da Amazônia nas comunidades da Fazendinha e Poção na ilha de Cotijuba. Inicialmente observouse que, mesmo de forma incipiente, o projeto tem como pontos positivos o envolvimento comunitário e a busca de parcerias com entidades públicas e privadas do setor turístico. Nesse sentido, torna-se fundamental a ampliação dessas parcerias, pois podem suprir lacunas deixadas pela ausência de recursos técnicos e financeiros para a execução de determinadas ações.

Atualmente a Amazônia é uma floresta urbanizada, sua população está majoritariamente concentrada nas cidades e nos núcleos urbanos, o que significa a presença dos principais impactos negativos no que tange ao meio ambiente, à sociedade e à economia.

Neste cenário, os problemas ambientais perpassam a situação social da população, a percepção acerca do meio que a circunda e uma série de outras variáveis que, concomitantemente ao crescimento populacional e ao adensamento humano nas sedes municipais, constroem e reconstroem o espaço como produto das relações sociais, como postula Milton Santos.

Iniciativas como a do Ecomuseu da Amazônia se traduzem em novas perspectivas de desenvolvimento, pois o turismo não pode ser entendido como a salvação para os problemas socioambientais das comunidades, mas sim como um fator agregador às atividades já implementadas, contribuindo à sustentabilidade econômica, social e ambiental. Entende-se o turismo de base comunitária como uma dimensão do turismo sustentável, o qual possui um cunho voltado à educação ambiental, ao empoderamento comunitário, e à valorização do patrimônio local.

O TBC surge em contraponto aos modelos e aos segmentos turísticos tradicionais, pois está baseado no protagonismo comunitário no desenvolvimento e no planejamento das atividades turísticas.

O Ecomuseu da Amazônia tem um papel fundamental como facilitador do processo de compreensão e assimilação das possibilidades que envolvem o trabalho no turismo de base comunitária, portanto a interdisciplinaridade dos eixos de atuação do Ecomuseu da Amazônia possibilita um aprofundamento técnico, teórico e prático por parte da comunidade acerca do seu patrimônio.

Enfim, este estudo possibilitou vislumbrar o trabalho do Ecomuseu no fomento ao turismo de base comunitária, de forma a relacionar o conceito oriundo da nova museologia à preservação ambiental e à valorização do patrimônio cultural de comunidades tradicionais, a exemplo da Fazendinha e do Poção, cumprindo o seu papel como agente de desenvolvimento territorial sustentável.

\section{Referências}

ANDRADE, Rita de C. G de. (2010). Política nacional de Ordenamiento Territorial: el caso de Brasil. Espacio y Desarrollo $\mathrm{N}^{\circ} 22$, pp. 119-134.

BELÉM, Coordenadoria Municipal De Turismo. (1998). Inventário Turístico e Ecológico da Ilha de Cotijuba, Belém-Pa.

BELÉM. ECOMUSEU DA AMAZÔNIA. (2016). Pesquisa de Perfil Socioeconômico das Comunidades da Fazendinha e Poção. Projeto de TBC-Ilha de Cotijuba. Fundação Centro de 
Referência em Educação Ambiental Escola Bosque Professor Eidorfe Moreira - FUNBOSQUE, Belém-PA.

BELÉM. FUNDAÇÃO ESCOLA BOSQUE. (1998). Inventário biológico e do potencial ecoturístico da Ilha de Cotijuba, Belém-PA (relatório preliminar). Belém: FUNBOSQUE.

BENEVIDES, I.P. (2002). Para uma agenda de discussão do turismo como fator de desenvolvimento local. In: RODRIGUES, A.B. (Org.) Turismo e desenvolvimento local. 3. ed. São Paulo: Hucitec, P.23-41.

BOHAN, H de Varine. (2009). Relatório de Missão: consultoria realizada nas áreas de atuação do Ecomuseu da Amazônia - Ilhas de Caratateua e Cotijuba e Distrito de Icoaraci. Belém - PA, 19p.

CORDIOLI, Sergio. (2001). Enfoque Participativo: um processo de mudança. Porto Alegre: Gênesis.

CORIOLANO, L. N. M. T. ; SANSOLO ; MENDONÇA. (2009). O Turismo Comunitário no Nordeste Brasileiro. In: Bartholo Roberto; Sansolo Davis Gruber; Bursztyn Ivan. (Org.). Turismo de Base Comunitária: Diversidade de Olhares e Experiências Brasileiras. 1a ed. Rio de Janeiro: Letra e Imagem.

CRUZ, R.C.A. (2007) Geografia do Turismo: de lugares a pseudo lugares. São Paulo, Roca.

DESLANDES, S. F.; MINAYO, Maria Cecília de Souza (org.). (2011). Pesquisa social: teoria, método e criatividade. 30. ed. Petrópolis, RJ: Vozes.

DIEGUES, Antônio Carlos. (1997). Ilhas e Sociedades Insulares. NUPAUB- Núcleo de apoio à pesquisa de populações humanas e áreas úmidas brasileiras - USP

FONSECA, Igor. F. da. (2007). Mercadores de moralidade: a retórica ambientalista e a prática do desenvolvimento sustentável. Ambiente \& Sociedade. Campinas v. X, n. 2. p. 171-188. jul. Dez.

GUERRA, Gutemberg. (2007). A. Os Efeitos da Ocupação Urbana no Extrativismo Vegetal da Ilha de Cotijuba. Belém-PA, Unama.

GUERRA, G. A. D; CARVAlHO, V. R. V. de. (2003). Ruralidade na Capital do Estado do Pará. Permanências e Mudanças na Ilha de Cotijuba. In Conservação e desenvolvimento no estuário e litoral amazônicos, Aragon, Luis E. (org.). BELÉM. . UFPA/NAEA, p.210-211.

HELLER, A. (2000). O cotidiano e a história. São Paulo: Paz e Terra.

HOMMA, Alfredo K. O. (2005). Amazônia: como aproveitar os benefícios da destruição? Estudos Avançados 19 (54).

HUFFNER, J. G. P.; BELLO, L. A. L. (2012). Análise dos Impactos Ambientais da Expansão Urbana na Ilha de Cotijuba, Belém-Pa. Caminhos de Geografia (UFU), v. 13, p. 286-298.

HUFFNER, J. G. P.; BELLO, L. A. L. (2013). Turismo e Indicadores de Sustentabilidade Ambiental na Ilha de Cotijuba. Educação Ambiental em Ação, v. 5, p. 1-10.

LAKATOS, Eva Maria. (2003). Fundamentos de metodologia científica. Marina de Andrade Marconi, Eva Maria Lakatos. - $5^{\circ}$. ed. - São Paulo: Atlas.

LOUREIRO, E. C. (2005). Comentários à Legislação Ambiental. Belém: SECTAM.

MALDONADO, C. (2008). Fortalecendo as redes de turismo comunitário na América Latina. Acedido em 16/12/2009, http://www. turismoresponsable.org.

MARTINS, Alan Kalil Abdon. (2003). A ruralidade da ilha de Cotijuba: Um olhar etnográfico. Revista Lato \& Sensu, Belém, v. 4, n. 1, p. 3-5, out.

MARTINS, Maria Teresinha Resende. (2010). Ecomuseu: Uma alternativa de gestão ambiental. Press color, Belém-Pa.

MARTINS, M.T.R.; ADERNE, L. (2007). Projeto Ecomuseu da Amazônia. Belém-PA. p 55.

MELO, Odimar do Carmo. (2008). A comunidade e a construção do lugar na Ilha de Cotijuba (PA). EGPA (Escola de Governo do Estado do Pará) Programa de Pós-graduação em Geografia - PPGEO/UFPA.

MOTA, G. (2008). Entre a comunidade e o lugar: aportes teóricos para um debate. In: ROCHA, G. M et al (org). Coletividade locais e desenvolvimento territorial na Amazônia. Belém: NUMA/UFPA.

NÓBREGA, Wilker Ricardo de Mendonça. (2006). Participação popular e as políticas públicas de turismo na Amazônia: O Proecotur no distrito de Mosqueiro, Belém-PA, Universidade Federal da Bahia - UFBA.

PEREIRO, X. (2002). Do Museu ao Ecomuseu: Os novos usos do patrimônio cultural. Universidade de Vigo.

SANSOLO, Davis Gruber; BURSZTYN, Ivan. (2009). Turismo de Base Comunitária: potencialidade no espaço rural brasileiro. In: BARTHOLO, R; SANSOLO, DAVIS GRUBER; BURZRSTYN, IVAN. (Org.). Turismo de Base Comunitária: diversidade de olhares e experiências brasileiras. 1ed. Rio de Janeiro: Letra e Imagem, v. 1, p. 142-161.

SILVA, Sérgio Brazão de. (2010). Belém e o ambiente insular. Belém, Ed. Da Universidade Federal Rural da Amazônia - UFRA.

SWINGLERHURST, Edmund. (2002). Turismo Global: Os Efeitos do Turismo nas Sociedades do Passado e nas Atuais. São Paulo, Editora Senac.

TUCUM. Rede Cearense de Turismo Comunitário. 
(2008). Presentation held at the II International Seminar on Sustainable Tourism. Fortaleza.

WAGLEY, Charles. (1954). Estudos de comunidade no Brasil sob perspectiva nacional. Sociologia, v. 16, n. 2, p. 3-22.

VALLADARES, Maurício de B. e C. (2009). Entre a natureza e o artifício: percepções e perspectivas para parques urbanos e orlas fluviais na Amazônia. Estudos Urbanos e Regionais v.11, N.1/maio.

\section{Contribuição dos autores na construção} do artigo

Huffner: Pesquisa de campo, bibliográfica, coleta de dados, digitação do texto.

Martins: Revisão textual e metodológica.

Bastos: Revisão textual, correção ortográfica e pesquisa documental e bibliográfica. 